Б.И. Гончаренко ${ }^{1,3}$, А.И. Веденев ${ }^{2}$ Е.В. Медведева ${ }^{1,2}$, А.С. Шуруп ${ }^{1,2,3}$

\title{
ИСПОЛЬЗОВАНИЕ ИНФОРМАЦИИ О СКАЛЯРНО-ВЕКТОРНЫХ ХАРАКТЕРИСТИКАХ АКУСТИЧЕСКОГО ПОЛЯ ПРИ ВОССТАНОВЛЕНИИ ПАРАМЕТРОВ МЕЛКОГО ВОДОЕМА
}

\author{
${ }^{1}$ МГУ имени М.В. Ломоносова, физический факультет \\ Россия, 119992, ГСП-2, Москва, Ленинские горы, 1/2, \\ Teл.+7(495)939-30-81,E-mail: goncharenko@phys.msu.ru \\ ${ }^{2}$ Институт океанологии им. П.П. Ширшова РАН \\ Россия, 117218, Москва, Нахимовский пр., 36, \\ Тел.+7(495)380-41-50,E-mail: vedenev@ocean.ru \\ ${ }^{3}$ Институт физики Земли им. О.Ю. Шмидта РАН \\ Россия, 123242, Москва, Б. Грузинская ул., 10/1, \\ Тел.: +7(499)254-90-80,E-mail: shurup@physics.msu.ru
}

\begin{abstract}
Приводятся результаты экспериментов, проведенных с использованием комбинированных приемных модулей, осуществлявших регистрацию давления и трех взаимно ортогональных проекций колебательной скорости. Измерения проводились в различных гидрологических условиях - в устье реки и вдали от береговой линии. Сравнение экспериментальных результатов и данных численного моделирования демонстрирует возможность оценки параметров волновода по данным в виде пространственного затухания скалярно-векторных характеристиках акустического поля.
\end{abstract}

Ключевые слова: методы измерения векторной фазы, пространственное затухание звука на мелководье, векторный приемник, газонасыщенные осадки

Исследование особенностей пространственного затухания скалярно-векторных характеристик акустического поля в водном слое является актуальной задачей [1], решение которой используется для оценки дальности действия гидроакустического оборудования, исследования влияния антропогенного шума на ихтиофауну [2]. В настоящей работе обсуждаются возможности использования информации о пространственном затухании составляющих акустического поля для решения задачи оценки параметров волновода. Рассматриваются результаты двух 
экспериментов, проведенных с использованием комбинированных приемных модулей (КПМ), которые содержат приемник звукового давления и векторный приемник.

В одном случае экспериментальные работы проводились на акватории Клязьминского водохранилища на гидроакустическом полигоне МГУ [3]. Вдали от берега был выбран протяженный в горизонтальном направлении ровный участок глубиной $\approx 8$ м. Известно [4], что место проведения работ характеризуется сложными условиями распространения, вызванными присутствием в толще дна акватории газонасыщенного слоя ила, что приводит к существенному уменьшению скорости звука в дне до величин $\approx 100$ м/с и значительному затуханию сигналов при распространении.

В другом случае экспериментальные работы проводились в русле реки Урал [5]. Наблюдался практически прямоугольный волновод, ограниченный по бокам отвесными берегами. Средняя глубина водного слоя вдоль трассы измерений составляла примерно $\approx 5$ м. Скорость звука по глубине водного слоя постоянна и равна 1483 м/с, эффективная скорость звука в верхнем слое осадков примерно 250 м/с [2]. Таким образом, как и в акватории Клязьминского водохранилища, так и в русле реки Урал, скорость звука в грунте понижена по отношению к скорости звука в водном слое.

В обоих экспериментах были записаны сигналы от приповерхностного шумового источника, в качестве которого выступали суда, проходящие мимо места установки КПМ. Расстояния до источников в различные моменты времени в обоих случаях фиксировались с помощью лазерного дальномера. В качестве примера, на рис. 1а, б представлены проходные характеристики источников в виде спектрограмм сигналов, записанных по каналу давления. На рис. 1а, б наблюдается интерференционная структура поля в виде набора чередующихся полос, угол наклона которых изменяется по мере изменения расстояния от КПМ до источника. На рис. 1в, г изображены пространственные убывания давления $p$ и вертикальной компоненты колебательной скорости $v_{z}$, вычисленные стандартным образом $[3,5]$ в треть октавной полосе с центральной частотой 530 Гц. При расчетах выбирались одинаковые для обоих экспериментов расстояния до источника, также учитывалась разная скорость судов. На рис. 1в, г видно, что помимо убывания с расстоянием, в обоих экспериментах уровни $p$ и $v_{z}$ испытывают выраженные вариации, вызванные интерференцией шумового поля в волноводе, причем пространственный период интерференционных биений в обоих экспериментах примерно совпадает, в виду того, что глубина волновода отличается не так суще- 

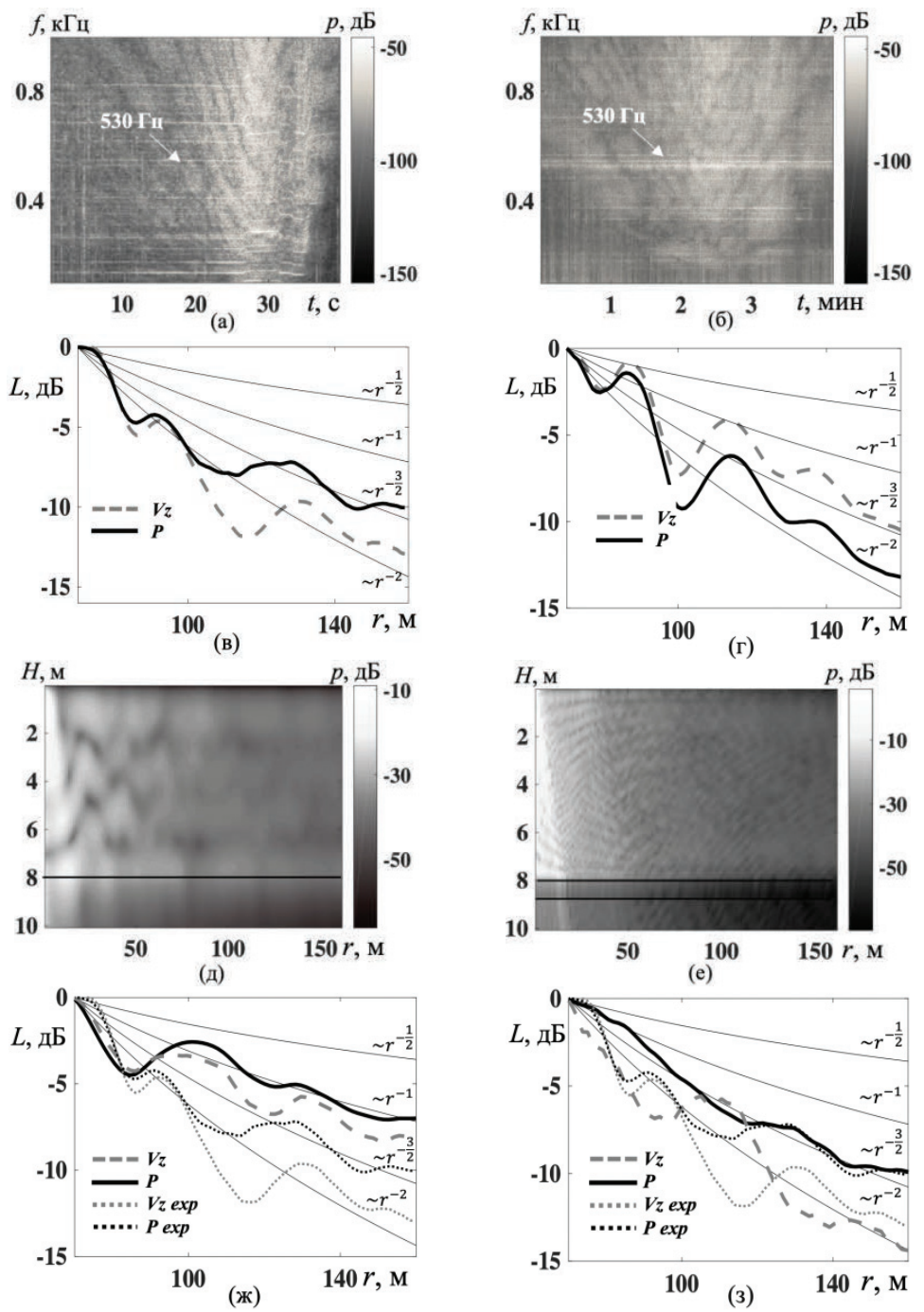

Рис. 1 (а-г). Спектрограмма сигналов, зарегистрированных на канале $p$ при прохождении источника в эксперименте на Клязьминском водохранилище (а), нар. Урал (б) и соответствующие экспериментальные убывания $p, v_{z},($ в), (г). (д-3). Распределение уровней звукового давления для условий Клязьминского водохранилища при отсутствии в дне газонасыщенного слоя (д), и при его наличии (e), а также соответствующие теоретические убывания $p$ и $v_{z}(ж),(3)$. 
ственно, а при обработке используется одинаковый частотный диапазон. При этом характер убывания $p$ и $v$ в экспериментах различный: на начальном участке (до 80 м) в р. Урал затухание как $p$, так и $v_{z}$, более сильное по сравнению с Клязьминским водохранилищем, причем характер затухания практически одинаков для этих составляющих поля. На больших же расстояниях наблюдается отличие уже в поведении $p$ и $v_{z}$ - на р. Урал сильнее затухает $p$, чем $v_{z}$, в то время как на Клязьминском водохранилище ситуация обратная. Наблюдаемые особенности убывания $p$ и $v_{z}$ в виде интерференционных биений, а также различного характера убывания этих компонент акустического поля $\left(v_{x}, v_{y}\right.$ демонстрируют аналогичные особенности), определяются параметрами волновода, что позволяет говорить о возможности оценки параметров волновода на основе анализа этих зависимостей. В качестве примера, на рис. 1д, е приведены уровни давления $p$, рассчитанные для условий Клязьминского водохранилища, отличающихся только параметрами дна - двухслойная модель грунта с газонасыщенным слоем, а также дно в виде полупространства. Параметры дна брались из работы [4]. Расчеты выполнены на основе метода параболического уравнения с использованием программы, разработанной К.В. Авиловым [6]. Пространственное убывание $p$ и $v_{z}$, соответствующее условиям проведения эксперимента, представлено на рис. 1ж, з. Как видно на рис. 1ж, 3, численные результаты повторяют характерные особенности, полученные в эксперименте, - наблюдаются похожие интерференционные биения, повторяется и характер затухания $p$ и $v_{z}$ на больших расстояниях. В итоге параметры, использованные при моделировании, могут рассматриваться в качестве приближенной оценки характеристик волновода. Следует отметить, что точного совпадения экспериментальных и расчетных кривых убывания не наблюдается, что говорит о возможности дальнейшего улучшения оценок. Вместе с тем, полученные результаты указывают на принципиальную возможность решения обратной задачи восстановления параметров волновода по данным в виде пространственных затуханий составляющих акустического поля. При этом принципиально важным является использование информации как о давлении, так и о проекциях колебательной скорости. В этом случае объем независимых данных для решения обратной задачи возрастает, что благоприятно сказывается на ее решении. Детальный анализ подобной обратной задачи, в том числе, возможно не единственности ее решения, относится к перспективам дальнейших исследований.

Работа выполнена при поддержке РФФИ, гранты 18-05-70034, 18-05-00737, а также гранта Президента РФ для научных школ № НШ 5545.2018.5. 


\title{
Литература
}

1. Белов А.И., Кузнецов Г.Н. Пространственное затухание различных составляющих звуковых полей в водном слое и осадках мелкого моря // Акустический журнал. 2017. Т. 63. № 6. С. 614-622.

2. Веденев А.И., Луньков А.А., Шатравин А.В., Кочетов О.Ю. Измерения шумов судна на воздушной подушке с целью оценки антропогенного воздействия на орнито- и ихтиофауну дельты р. Урал // Доклады XVI школы-семинара им. акад. Л.М. Бреховских, совмещенной с XXXI сессией Российского Акустического Общества. М.: ГЕОС, 2018. C. $177-180$.

3. Медведева Е.В., Гончаренко Б.И., Шуруп А.С. Использование разнесенных в пространстве комбинированных приемных модулей для исследования скалярно-векторных характеристик акустического поля // Известия РАН. Серия физическая. 2020. Т. 84. № 2. С. $278-283$.

4. Гончаренко Б.И., Захаров Л.Н., Иванов В.Е. О волновых числах и разности фаз между компонентами звукового поля в трехслойном волноводе // Акустический журнал. 1979. T. 25 , № 4. С. $507-514$.

5. Гончаренко Б.И., Веденев А.И., Шуруп А.С. Особенности распространения звукового сигнала в мелком пресном водоеме при разной глубине погружения источника звука // Вестник Московского Университета. Серия 3. Физика. Астрономия. 2019. № 5. C. $81-87$.

6. Авилов К.В. Псевдодифференциальные параболические уравнения распространения звука в океане, плавно неоднородном по горизонтали, и их численное решение // Акустический журнал. 1995. Т. 41. № 1. С. 5-12.

\section{B.I. Goncharenko ${ }^{1,3}$, A.I. Vedenev ${ }^{2}$, E.V. Medvedeva ${ }^{1,2}$, A.S. Shurup ${ }^{1,2,3}$}

\section{ABOUT THE POSSIBILITY OF EVALUATING THE PARAMETERS OF A SHALL WATER BASIS ON THE DATA ON THE SPATIAL ATTENUATION OF THE SCALAR VECTOR CHARACTERISTICS OF THE ACOUSTIC FIELD}

\author{
${ }^{1}$ Faculty of Physics, M.V. Lomonosov Moscow State University \\ Russia, 119991, Moscow, Leninskie Gory, 1/2, \\ Tel.: 8(495)939-3081; E-mail: goncharenko@phys.msu.ru \\ ${ }^{2}$ Shirshov Institute of Oceanology, Russian Academy of Sciences \\ Russia, 11799736, Moscow, Nakhimovskiy prospekt, 36, \\ Tel.: 8(495) 380-4150; E-mail: vedenev@ocean.ru \\ ${ }^{3}$ Shmidt Institute of the Physics of the Earth, Russian Academy of Sciences \\ Russia, 123242, Moscow, Bolshaya Gruzinskaya str., 10-1, \\ Tel.: (499) 254-90-80; E-mail: shurup@physics.msu.ru
}

The results of experiments conducted by using combined receiving modules that record pressure and three mutually orthogonal components of particle velocity are presented. The measurements were carried out in different hydrological conditions - at the bed of the river and far from the coastline in Klyazma reservoir. Comparison of experimental results and numerical 
simulation data demonstrates the possibility of estimating waveguide parameters by using information about spatial decay of scalar-vector characteristics of the acoustic field.

Keywords: vector-phase measurement methods, spatial attenuation of sound in a shallow water, vector receiver, gas-saturated precipitation

Acknowledgments: This work was supported by the Russian Foundation for Basic Research, grants No. 18-05-70034, 18-05-00737, as well as by the grant of the President of the Russian Federation for scientific schools No. NSh 5545.2018.5.

\section{References}

1. Belov A.I. and Kuzneczov G.N. Prostranstvennoe zatukhanie razlichny `kh sostavlyayushhikh zvukovy`kh polej v vodnom sloe i osadkakh melkogo moray. Akusticheskij zhurnal, 2017, Vol. 63, No. 6, pp. 614-622.

2. Vedenev A.I., Lun'kov A.A., Shatravin A.V., and Kochetov O.Yu. Izmereniya shumov sudna na vozdushnoj podushke s czel'yu oczenki antropogennogo vozdejstviya na ornitoi ikhtiofaunu del'ty' r. Ural. Proc.' XVI shkoly-seminara im. akad. L.M. Brekhovskikh, sovmeshhennoj s XXXI sessiej Rossijskogo Akusticheskogo Obshhestva, Moscow: GEOS, 2018, pp. 177-180.

3. Medvedeva E.V., Goncharenko B.I., and Shurup A.S. Ispol'zovanie raznesenny'kh v prostranstve kombinirovanny'kh priemny'kh modulej dlya issledovaniya skalyarnovektorny'kh kharakteristik akusticheskogo polya. Izvestiya RAN, Seriya fizicheskaya, 2020, Vol. 84, No. 2, pp. 278-283.

4. Goncharenko B.I., Vedenev A.I., and Shurup A.S. Osobennosti rasprostraneniya zvukovogo signala $\mathrm{v}$ melkom presnom vodoeme pri raznoj glubine pogruzheniya istochnika zvuka. Vestnik Moskovskogo Universiteta, Seriya 3, Fizika, Astronomiya, 2019, No. 5, pp. 81-87.

5. Goncharenko B.I., Zakharov L.N., and Ivanov V.E. O volnovy'kh chislakh i raznosti faz mezhdu komponentami zvukovogo polya v trekhslojnom volnovode. Akusticheskij zhurnal, 1979, Vol. 25, No. 4, pp. 507-514.

6. Avilov K.V. Psevdodifferenczial`ny`e parabolicheskie uravneniya rasprostraneniya zvuka $\mathrm{v}$ okeane, plavno neodnorodnom po gorizontali, i ikh chislennoe reshenie. Akusticheskij zhurnal, 1995, Vol. 41, No. 1, pp. 5-12. 